\title{
Stock structure and resource management of hairtail Trichiurus japonicus based on seasonal broods around the Bungo Channel, Japan
}

\author{
Shingo Watari ${ }^{1} \cdot$ Syunji Tokumitsu $^{2} \cdot$ Taro Hirose $^{3,4} \cdot$ Michio Ogawa $^{3}$. \\ Mitsutaku Makino ${ }^{1}$
}

Received: 31 January 2017 / Accepted: 30 June 2017 / Published online: 1 November 2017

(c) The Author(s) 2017. This article is an open access publication

\begin{abstract}
Declines in landings of the hairtail Trichiurus japonicas indicate the need for more effective management of this species. Hairtail spawning peaks occur twice yearly in the Bungo Channel, in spring and autumn. Relationships between hairtail stock and brood seasonality were examined to determine if an association between either and a decline in landings existed. Stock assessments show that the biomass of both spring and autumn hairtail broods from within and around the Bungo Channel are decreasing, with a rapid reduction in spring-brood stock abundance after 2007 largely
\end{abstract}

Shingo Watari

swatari@affrc.go.jp

Syunji Tokumitsu

tokumitsu-syunji@pref.oita.lg.jp

Taro Hirose

taro@affrc.go.jp

Michio Ogawa

ogawa@jamarc.go.jp

Mitsutaku Makino

mmakino@affrc.go.jp

1 National Research Institute of Fisheries Science, Japan Fisheries Research and Education Agency, 2-12-4, Fukuura, Kanazawa-ku, Yokohama, Kanagawa 236-8648, Japan

2 Fisheries Research Division, Oita Prefectural Agriculture, Forestry and Fisheries Research Center, 42 Ajimumachisho, Usa, Oita 872-0504, Japan

3 Marine Fisheries Research and Development Center, Japan Fisheries Research and Education Agency, 15F Queen's Tower B, 2-3-3 Minatomirai, Nishi-ku, Yokohama, Kanagawa 220-6115, Japan

4 Present Address: National Research Institute of Fisheries and Environment of Inland Sea, Japan Fisheries and Education Agency, 2-17-5, Maruishi, Hatsukaichi, Hiroshima 739-0452, Japan responsible for decreased landings. Yield and spawning per recruitment analyses indicate current fishing pressure to be higher than several reference points. We suggest that fishing pressure needs to be reduced by at least $20 \%$ of the current level for this fishery to remain sustainable, as the projected stock abundance and catch demonstrate that the current fishing pressure is unsustainable. Analysis of time-series data of recruits per spawning revealed spring-brood recruitment to have been strong in year classes 2003 and 2005. Of various options available for improved management of this fishery, we propose that fishing pressure should be reduced in the years following the appearance of strong year classes to increase future biomasses and landings.

Keywords Spawning season - Strong year class · Virtual population analysis - Stock management $\cdot$ Stock abundance

\section{Introduction}

Hairtail Trichiurus japonicas is a widely distributed commercially exploited fish species found around Japan and the waters of the Yellow, Bohai, and East China Seas [1]. Several major fishing grounds exist around Japan, including the East China Sea, the western region of the Sea of Japan, and the waters around the Kii and Bungo Channels (Fig. 1). Though large numbers of hairtail were landed from both the East China Sea and western region of the Sea of Japan [2, 3] in the 1960s, the annual catch in these areas has decreased since the 1970s. However, landings of hairtail from waters around the Bungo Channel have increased from the 1970s, increasing the importance of these fishing grounds (Fig. 2). Waters within and around the Bungo Channel provide an important hairtail habitat, where most of the life cycle of this 


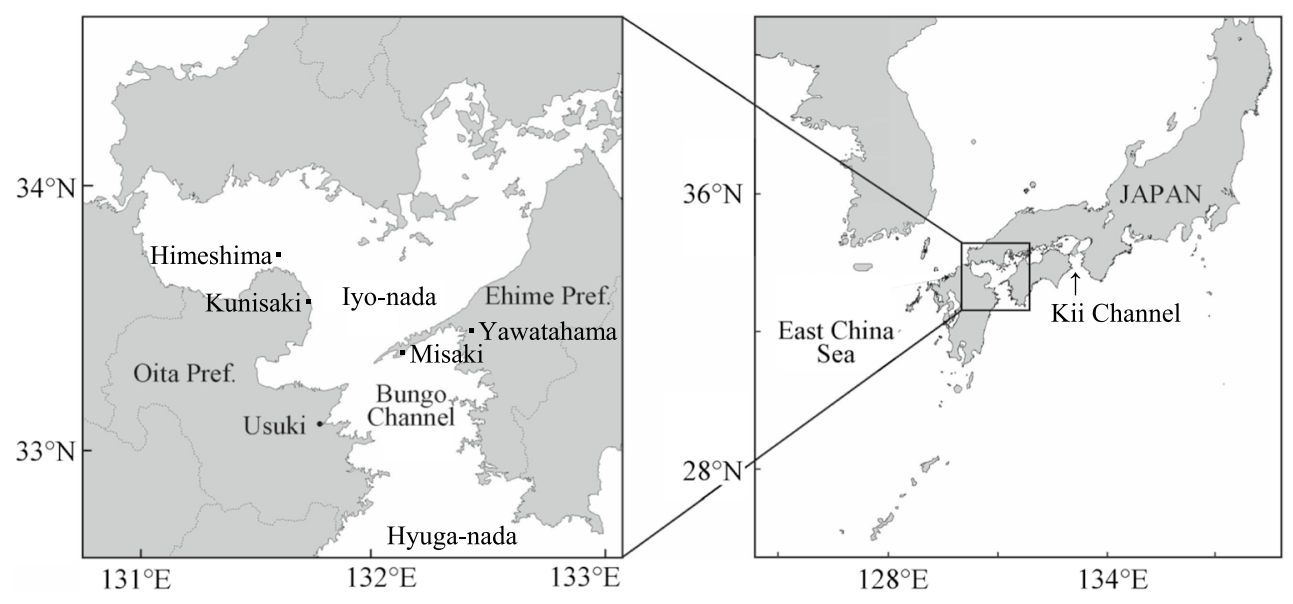

Fig. 1 Location of survey area

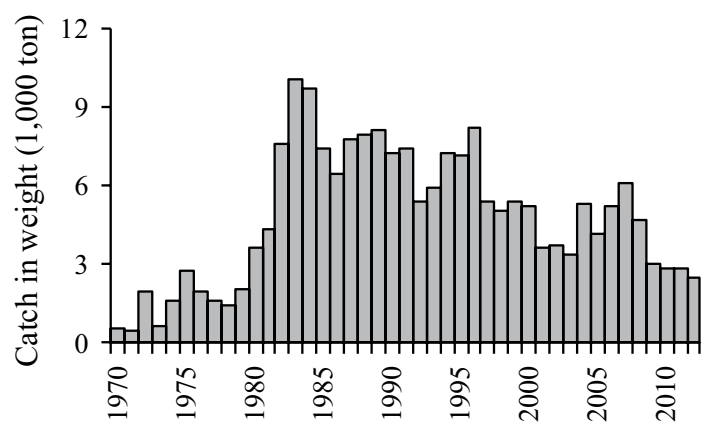

Fig. 2 Catch (landings) of hairtail by year in the Bungo Channel, Japan

species occurs $[2,4]$. The area is considered to be a single unit for fisheries resource management. Hairtail landings from the adjacent mid-western part of the Seto Inland Sea and Hyuga-nada are less than those around the Bungo Channel, with tagging experiments suggesting emigration from the Bungo Channel to be limited [2].

Spawning around the Bungo Channel is thought to occur from March to December, with peaks in May-June and September-October [4]. The spring brood comprises individuals spawned during the first peak (May-June), and the autumn brood those spawned during the second peak (September-October). In both broods the annual otolith ring forms from June to August, and thus the radius of the first annual ring in the spring brood is greater than that of the autumn brood. Consequently, spawning season can be determined for each fish, even for older individuals, based on the first otolith ring radius $[4,5]$. This characteristic has also been observed in hairtail from other areas [1, 6, 7]. Because of decreased winter growth, an age-length relationship using an extended von Bertalanffy growth model that takes seasonal growth variation into consideration using a periodic function is more suitable than a traditional von Bertalanffy growth model [4, 5]. At a pre-anal length of $250 \mathrm{~mm}, 50 \%$ of the females were mature [4], which corresponds to 1 year after hatching for both broods.

Around the Bungo Channel, hairtail is caught in trolling and net fisheries, the latter including purse seine and trawl fisheries. The quality of fish caught by trolling is greater than that caught by net, which is reflected in the market price, being higher for the former. The large quantities of hairtail caught using nets are processed mainly into fish paste. Though hairtail is one of the most important catchable resources in this area for both fisheries and the processing industry, landings of it have decreased since the late 1990s (Fig. 2). Preliminary stock assessments suggest it will be difficult to maintain the current biomass with current fishing pressure [8].

Historical catch data reveal that the hairtail population increases and decreases every few years. Although the catch has tended to decrease from 2007 (Fig. 2), the reason for this is not clear. Hairtail stock in the Bungo Channel comprises two different spawning broods, with changes in abundance resulting from changes in the proportions of these two seasonal brood groups [5]. However, previous Japanese hairtail stock assessment studies have not taken these seasonal broods into consideration $[3,8,9]$. We analyzed the stock structure by considering seasonal broods in this study, and identify likely reasons for recent decreases in the catch from this area. We endeavor to describe biological reference points based on yield per recruitment (YPR) and spawning biomass per recruitment (SPR) analysis, and discuss ways for more sustainable management of this fishery.

\section{Materials and methods}

We use virtual population analysis (VPA) to estimate hairtail abundance [10]. Generally, VPAs are conducted using 
catch-at-age data according to year, but in the case of hairtail, there are two spawning peaks (spring and autumn). To consider spawning peaks separately, catch-at-age data were separately estimated for both broods. VPAs were constructed for 4-month intervals (January-April, May-August, and September-December).

\section{Catch-at-age}

Hairtail are caught by both trolling and net fisheries, with catches divided into two size classes: I (> $200 \mathrm{~g})$ and II $(<200 \mathrm{~g})$. Trolling catches only class I fish, which are further divided into five size sub-classes (king, large, medium, small, and mini). Net fisheries catch both class I and II fish. For trolling-caught fish, monthly catch weight data by size sub-category were collected from Kunisaki, Usuki, Himeshima, and Misaki, from 2003 to 2011. For net-caught fish, monthly catch weight data for classes I and II were collected from Yawatahama over the same period.

A total of 3,088 hairtail individuals were collected from 2006 to 2011. Body weight was measured to the nearest $0.1 \mathrm{~g}$, age was estimated from the number of otolith rings, and spawning season was estimated from the first annual ring radius in accordance with Yanagawa [4] and Watari et al. [5]. These data were used to convert size sub-class composition to age composition.

Catch-at-age of fish caught by trolling was estimated using monthly catch weight data (grouped by sub-size), fisheries statistics, and the age-weight relationship described by Kurosaka et al. [11]. For net-caught fish, class I age composition was assumed to be the same as that of troll-caught class I fish. Age composition of class II fish was estimated from total landing data and average weight of fish landed in Yawatahama $(160 \mathrm{~g})$. Total catch-at-age was estimated by adding catch-at-age from both trolling and net fisheries.

\section{Stock biomass}

The number of fish of brood $b$ [spring brood (1), autumn brood (2)]; age $a(0, \ldots, 5$, spring brood; $1, \ldots, 5$, autumn brood); period $p$ (1, January-April; 2, May-August; 3, September-December), in year $y(2003, \ldots, 2011), N_{b, a, y, p}$, was estimated using the following equations:

$$
\begin{aligned}
N_{b, a, y, p}= & N_{b, a, y, p+1} \exp (M)+C_{b, a, y, p} \exp (M / 2) \\
& (a=0, \ldots, 4, p=1,2)
\end{aligned}
$$

$$
\begin{aligned}
N_{b, a, y, p}= & N_{b, a+1, y+1, p-2} \exp (M)+C_{b, a, y, p} \exp (M / 2) \\
& (a=0, \ldots, 4, p=3) .
\end{aligned}
$$

Among these, $N_{b, a, y, p}$ of 5-year-old fish of all $y$ and $p$, and in September-December $(p=3)$ 2011, was estimated as follows:

$N_{b, a, y, p}=\frac{C_{b, a, y, p}}{1-\exp \left(-F_{b, a, y, p}\right)} \exp (M / 2)$.

The natural mortality coefficient, $M$, was estimated from longevity ( $M=2.5 /$ longevity) [12]. Longevity was assumed to be 5 years, the known maximum age of hairtail. The fishing mortality coefficient of $b, a, p$, in year $y, F_{b, a, y, p}$, was estimated as follows:

$F_{b, a, y, p}=-\ln \left(1-\frac{C_{b, a, y, p} \exp (M / 2)}{N_{b, a, y, p}}\right) \quad(a=0, \ldots, 4)$

$F_{b, 5, y, p}=F_{b, 4, y, p} \quad(a=5)$.

Among these, $F_{b, a, y, p}$ of September-December 2011 was estimated as follows:

$F_{b, a, 2011,3}=\frac{\sum_{g=1}^{G} F_{b, a, 2011-g, 3}}{\sum_{g=1}^{G} F_{b, 4,2011-g, 3}} F_{b, 4,2011,3} \quad(a=0, \ldots 4, G=5)$,

where $F_{b, 4,2011,3}$ is assumed to be equal to $F_{b, 5,2011,3}$, the same as in Eq. (5). Stock biomass was calculated by multiplying $N_{b, a, y, p}$ and the average body weight of $b, a, p, W_{b, a, p}$, estimated from the relationship between age and pre-anal length, and between pre-anal length and body weight (Table 1) [5]. A retrospective analysis was conducted to detect systematic trends in abundance estimates of the latest year [13]. For sensitivity check, uncertainty derived from Eq. (6) was evaluated by using a different value of $G(G=4$ and 6$)$.

\section{Spawning stock biomass and recruit per spawning}

Spawning stock biomass at both spawning peaks, May $(p=2)$ and September $(p=3)$, was estimated by summing the spawning stock biomass of spring and autumn broods, as follows:

$\mathrm{SSB}_{y, p}=\sum_{b=1}^{2} \sum_{a=1}^{5} N_{b, a, y, p} \times W_{b, a, p} \times m_{b, a, p}$, 
Table 1 Pre-anal length, body weight and maturity rate by age and month estimated from Yanagawa [4] and Watari et al. [5]

\begin{tabular}{|c|c|c|c|c|c|c|c|c|c|}
\hline & \multirow[t]{2}{*}{ Age (year) } & \multicolumn{3}{|c|}{ Pre-anal length (mm) } & \multicolumn{3}{|c|}{ Body weight (g) } & \multicolumn{2}{|c|}{$\begin{array}{l}\text { Maturity rate of } \\
\text { female }\end{array}$} \\
\hline & & January & May & September & January & May & September & May & September \\
\hline \multirow[t]{6}{*}{ Spring brood } & 0 & & & 183 & & & 95 & & \\
\hline & 1 & 221 & 231 & 289 & 161 & 184 & 343 & 0.43 & 0.78 \\
\hline & 2 & 316 & 323 & 363 & 437 & 465 & 645 & 0.91 & 0.97 \\
\hline & 3 & 381 & 386 & 414 & 739 & 767 & 930 & 0.99 & 0.99 \\
\hline & 4 & 427 & 430 & 449 & 1,011 & 1,035 & 1,169 & 1.00 & 1.00 \\
\hline & 5 & 458 & 460 & 474 & 1,233 & 1,251 & 1,354 & 1.00 & 1.00 \\
\hline \multirow[t]{5}{*}{ Autumn brood } & 1 & 115 & 133 & 234 & 26 & 39 & 190 & 0.06 & 0.46 \\
\hline & 2 & 265 & 276 & 338 & 268 & 299 & 527 & 0.71 & 0.94 \\
\hline & 3 & 357 & 363 & 401 & 613 & 645 & 850 & 0.97 & 0.99 \\
\hline & 4 & 412 & 416 & 439 & 919 & 944 & 1,097 & 0.99 & 1.00 \\
\hline & 5 & 446 & 449 & 463 & 1,147 & 1,164 & 1,269 & 1.00 & 1.00 \\
\hline
\end{tabular}

where $m_{b, a, p}$ is the maturity rate of female estimated from the relationship between age and pre-anal length, and between pre-anal length and maturity rate (Table 1) [4, 5]. Recruit per spawning (RPS) of year $y$ for spring and autumn spawning seasons was estimated as follows:

$\operatorname{RPS}_{\text {spring }}=N_{1,0, y, 3} / \mathrm{SSB}_{y, 2}$

$\operatorname{RPS}_{\text {autumn }}=N_{2,1, y, 1} / \mathrm{SSB}_{y, 3}$.

\section{Stock status and management scenarios}

Current fishing status was evaluated by using YPR and SPR analyses. YPR and SPR were estimated by summing the age of fish from first capture to 5 years for both broods using the following equations:

$$
\begin{aligned}
\mathrm{YPR}= & \sum_{a=0}^{5} \sum_{p=1}^{3} \frac{F_{1, a, p}}{F_{1, a, p}+M}\left(1-\exp \left(-F_{1, a, p}-M\right)\right) S_{1, a, p} W_{1, a, p} \\
& +\sum_{a=1}^{5} \sum_{p=1}^{3} \frac{F_{2, a, p}}{F_{2, a, p}+M}\left(1-\exp \left(-F_{2, a, p}-M\right)\right) S_{2, a, p} W_{2, a, p}(10) \\
S P R= & \sum_{a=0}^{5} \sum_{p=1}^{3} m_{1, a, p} S_{1, a, p} W_{1, a, p}+\sum_{a=1}^{5} \sum_{p=1}^{3} m_{2, a, p} S_{2, a, p} W_{2, a, p}
\end{aligned}
$$

$S_{b, a, p}=S_{b, a-1, p+2} \exp \left(-F_{b, a-1, p+2}-M\right) \quad\left(p=1, S_{2,1,1}=1\right)$

$S_{b, a, p}=S_{b, a, p-1} \exp \left(-F_{b, a, p-1}-M\right) \quad\left(p=2,3, S_{1,0,3}=1\right)$

where $S_{b, a, p}$ is the survival rate of $b, a$, and $p$. Several biological reference points, $F_{30 \% \mathrm{SPR}}$ [14], the $F_{0.1}[15]$ and a fishing mortality coefficient that produced the maximum YPR $\left(F_{\max }\right)$ were calculated and compared with the current fishing mortality coefficient $\left(F_{\text {current }}\right) \cdot F_{\text {current }}$ was defined as a mean value of all $F_{b, a, 2011, p}$.

Because recent hairtail landings have decreased, future abundance and catch trends for 20 years were estimated under reduced fishing pressure scenarios. The recruitment of both spring and autumn broods was estimated using the following equations:

$N_{1,0, y, 3}=\mathrm{SSB}_{y, 2} \times \overline{\operatorname{RPS}}_{\text {spring }}$

$N_{2,1, y+1,1}=\mathrm{SSB}_{y, 3} \times \overline{\mathrm{RPS}}_{\text {autumn }}$,

where $\overline{\mathrm{RPS}}_{\text {spring }}$ and $\overline{\mathrm{RPS}}_{\text {autumn }}$ are average values of RPS for both season. Other $N_{b, a, y, p}$ were estimated using the following equations:

$$
\begin{aligned}
N_{b, a, y, p} & =N_{b, a-1, y-1, p+2} \exp (-M) \\
& -C_{b, a-1, y-1, p+2} \exp (-M / 2) \quad(p=1)
\end{aligned}
$$


$N_{b, a, y, p}=N_{b, a, y, p-1} \exp (-M)-C_{b, a, y, p-1} \exp (-M / 2) \quad(p=2,3)$.

$C_{b, a, y, p}$ were estimated as follows:

$C_{b, a, y, p}=N_{b, a, y, p}\left(1-\exp \left(-(1-\alpha) F_{b, a, y, p}\right)\right) \exp (-M / 2)$,

where $\alpha$ is the rate of reduction in fishing pressure compared with current levels. Four different reduced fishing pressure scenarios were considered: reduction of fishing pressure throughout the year (YE), a halving of fishing pressure for 2 months during the spring spawning season (SP), a halving of fishing pressure for 2 months during autumn spawning season (AU), and a halving of fishing pressure in the year following the appearance of a strong year class (ST). Reduction rate $(\alpha)$ was set at $0,0.1,0.2$, and 0.3 in YE, 0.25 in SP and $\mathrm{AU}$, and 0.5 in ST, as a large reduction in fishing pressure might be an acceptable short-term measure. The effect of each reduced fishing pressure scenario was evaluated individually and in combination, i.e., SP and YE; AU and YE; ST and YE. For future recruitment, we forecast strong year classes would occur in the 5 th and 10 th years. For estimation of future spring-brood recruitment, mean RPS values were calculated for years in which year class appearance was strong, and for normal years. Rates of change in average catch and biomass after 20 years [catch(20 year)/ $\operatorname{catch}(0$ year $)$, and biomass(20 year)/biomass( 0 year)] were evaluated. The SEs of these values were calculated by a bootstrap method, resampling RPS values 1000 times.

\section{Results}

\section{Catch-at-age}

Catch-at-age showed a decreasing trend especially for the spring brood following 2007. Age at first capture for spring and autumn brood individuals was 0 year in September-December and 1 year in January-April, respectively. Fishing pressure on fish of ages 1 and 2 years is greater than it is on fish of ages 3-5 years (Appendix 1).

\section{Stock biomass}

Both spring and autumn brood stock abundance trended down (Fig. 3; Appendix 1), though spring-brood stock abundance rapidly declined after 2007. Spring-brood recruitment levels in 2003 and 2005 were at least three times greater than in other years. The reduction in stock abundance was less in
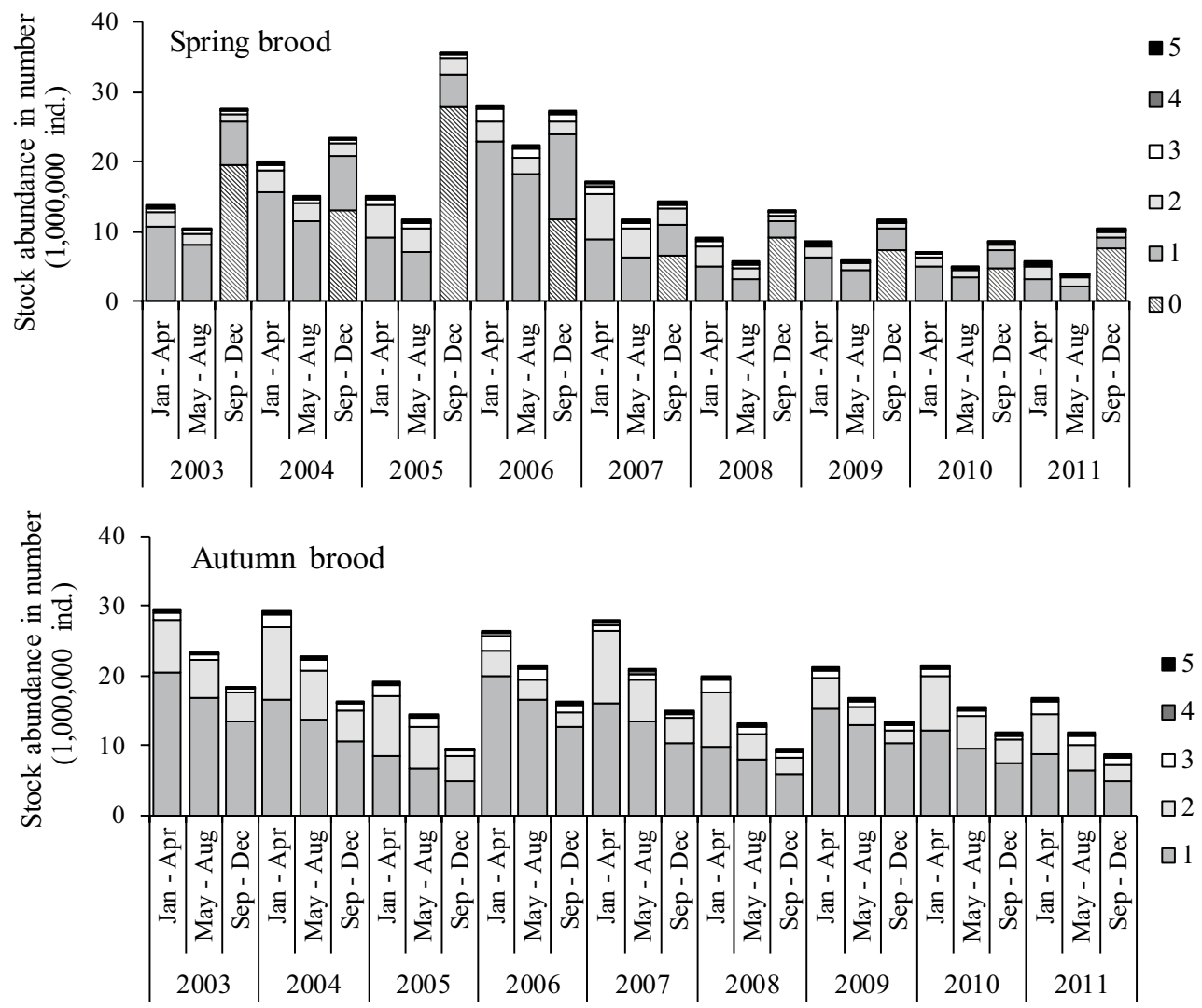

Fig. 3 Relationship between stock abundance, age (1-5; years), and spring and autumn hairtail broods 
Fig. 4 Retrospective analysis of stock biomass for both spring and autumn hairtail broods

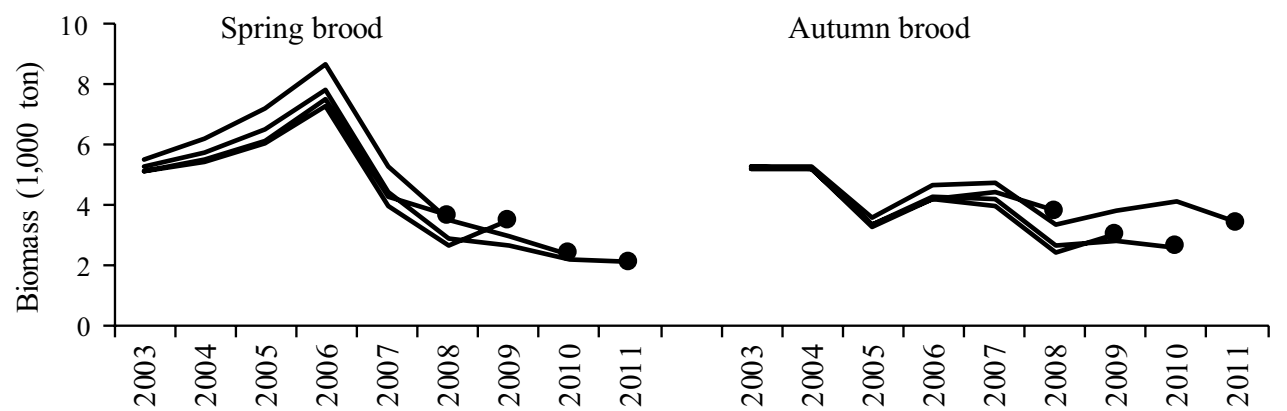

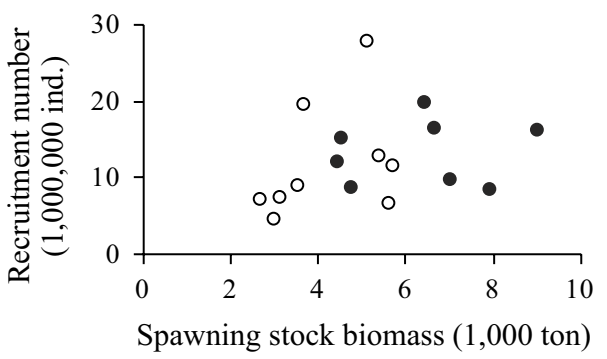

Fig. 5 Relationship between spawning stock biomass and recruitment in spring (open circles) and autumn (closed circles) hairtail broods

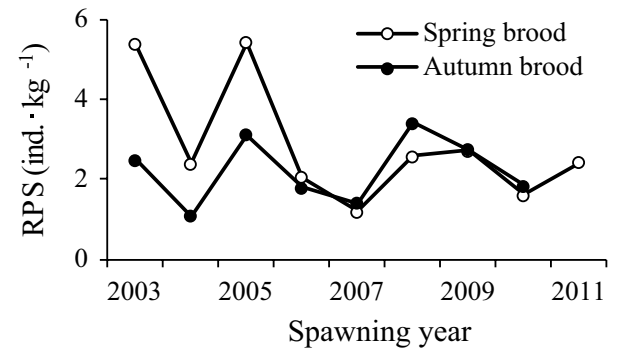

Fig. 6 Temporal variation in recruits per spawning (RPS) for spring and autumn hairtail broods

the autumn than for spring broods. Recruitment of autumn brood fish varied among years but remained relatively constant. A retrospective analysis identified no systematic trends in abundance estimates of the latest year (Fig. 4). Sensitivities of Eq. (6) of $G$ of stock biomass including both broods are 5,331 $\mathrm{t}(G=4), 5,176 \mathrm{t}(G=5)$, and 4,912 $\mathrm{t}(G=6)$; those of $F_{\text {current }}$ were $0.22(G=4), 0.22(G=5)$, and 0.24

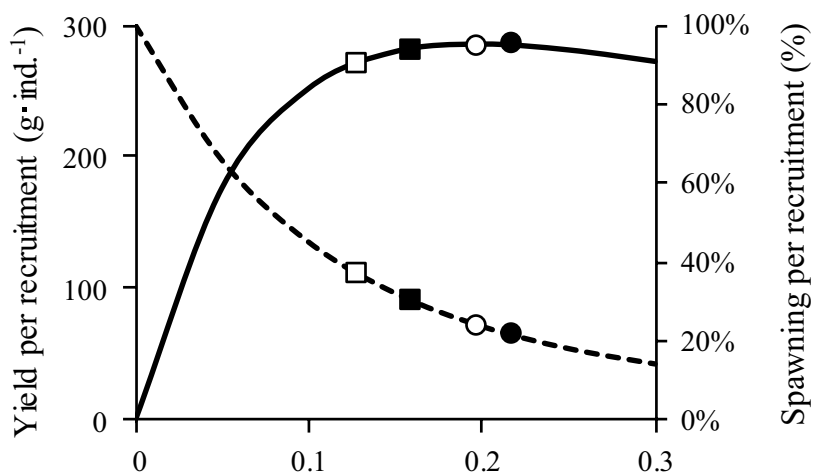

Fishing mortality coefficient $(F)$

Fig. 7 Yield per recruitment curves (solid line) and percentage of spawning per recruitment curves (dotted line) for hairtail. Current and reference point levels of fishing mortality coefficient $(F)$ are shown by closed circle $\left(F_{\text {current }}\right)$, open circle $\left(F_{\max }\right)$, closed square $\left(F_{30 \% \mathrm{SPR}}\right)$, and open square $\left(F_{0.1}\right)$

$(G=6)$. Similar trends are apparent for biomass and the fishing mortality coefficient.

There was no clear relationship between spawning stock biomass and recruitment in either spawning season (Fig. 5). Even at the same age, the maturity rate in the September-December period $(p=3)$ was higher than in the May-August period $(p=2)$ (Table 1). There is a tendency for the autumn spawning stock biomass to be greater than that of the spring (Fig. 5). Spring spawning season RPS values identified strong recruitment in 2003 and 2005, but lower recruitment in other years (Fig. 6). Strong recruitment occurred with a spawning stock biomass of 3,657-5,144 t (average 4,400 t), corresponding to a stock biomass of 5,672-6,823 t (average 6,247 t). Autumn spawning season RPS values varied between years but remained around 
Fig. 8 Projected stock biomass (right) and catch in weight (left) for various combinations of reduced fishing pressure: throughout the year $(Y E)$ with reduction rate $(\alpha)$ of $0,0.1,0.2$, 0.3 , for 2 months during the spring spawning season $(S P)$; for 2 months during the autumn spawning season $(A U)$; and in the year after the appearance of a strong year class (ST)

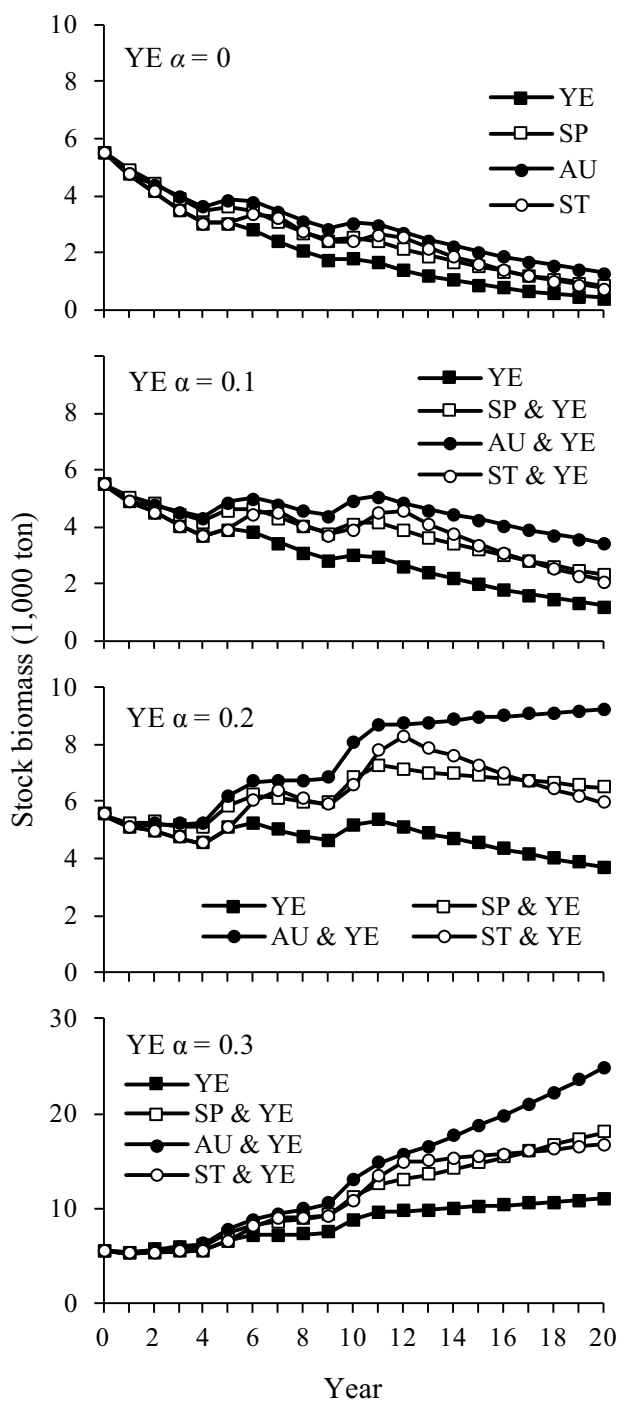

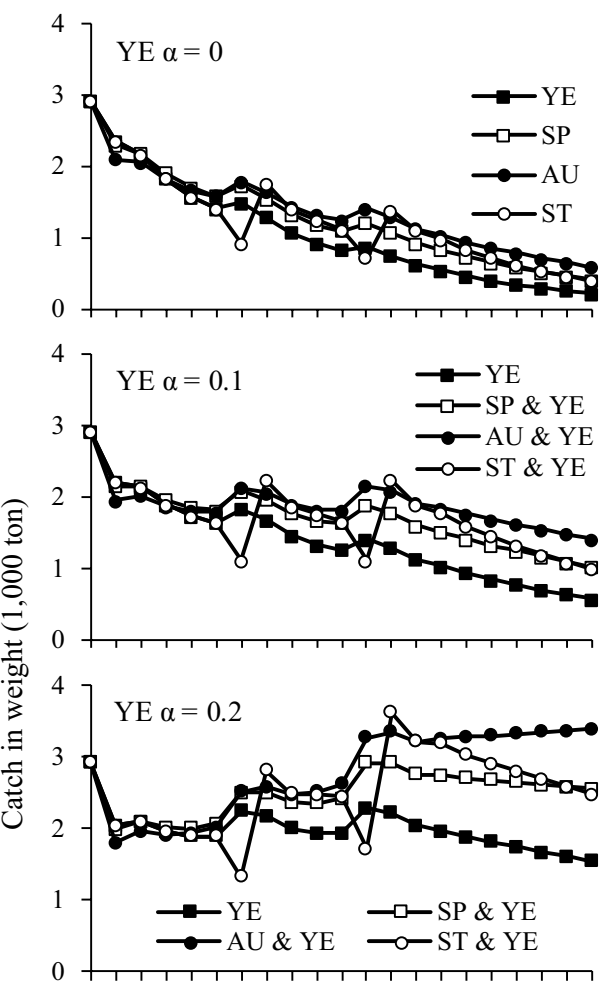

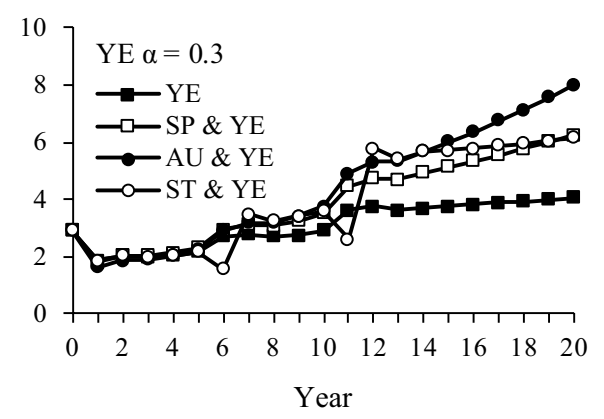

a certain level (Fig. 6), similar to the trend observed for recruitment.

\section{Stock status and management scenario}

Figure 7 depicts the relationship between the fishing mortality coefficient and YPR and percentage of SPR values. Current YPR levels and SPR percentages were 284 (g individual $^{-1}$ ) and $21 \%$, respectively. $F_{\text {current }}$ values and reference points are $F_{\text {current }}(0.22), F_{0.1}(0.13), F_{\text {max }}(0.20)$, and
$F_{30 \% \text { SPR }}(0.16)$. The current fishing mortality coefficient exceeds these reference points.

Figure 8 depicts projected stock abundance for various simulations, where the current level of fishing pressure will lead to decreases in both biomass and catch. In the event of a strong year class (strong recruitment), biomass and catch will subsequently increase, but if the rate of reduction in fishing pressure is low, any such benefit will disappear after 1 or 2 years (Fig. 8). If current fishing pressure is reduced by $20 \%$, stock levels in 20 years will remain comparable to those today. Of reduction methods of fishing pressure 
Table 2 Average catch over 20 years, and rate of change in catch and biomass in 20th year of reduction of fishing pressure: throughout the year $(Y E)$, for 2 months during the spring spawning season $(S P)$, for 2 months during the autumn spawning season $(A U)$, and in the year following the appearance of a strong year class $(S T)$
Table 3 Recruit per spawning (RPS) values of spring and autumn spawning seasons

\begin{tabular}{lllll}
\hline & $\begin{array}{l}\text { Reduction rate of fishing } \\
\text { mortality coefficient of YE }\end{array}$ & $\begin{array}{l}\text { Average catch during } \\
\text { 20 years }\end{array}$ & $\begin{array}{l}\text { Rate of change in } \\
\text { catch in 20th year }\end{array}$ & $\begin{array}{l}\text { Rate of } \\
\text { change in } \\
\text { biomass in } \\
\text { 20th year }\end{array}$ \\
\hline YE & 0 & $981(146)$ & $0.07(0.03)$ & $0.08(0.03)$ \\
SP & & $1,195(220)$ & $0.14(0.06)$ & $0.15(0.06)$ \\
AU & & $1,298(232)$ & $0.20(0.08)$ & $0.23(0.09)$ \\
ST & & $1,172(212)$ & $0.13(0.06)$ & $0.14(0.06)$ \\
YE & 0.1 & $1,326(241)$ & $0.20(0.08)$ & $0.22(0.09)$ \\
SP and YE & & $1,654(334)$ & $0.35(0.14)$ & $0.42(0.17)$ \\
AU and YE & & $1,832(395)$ & $0.48(0.20)$ & $0.62(0.25)$ \\
ST and YE & & $1,644(335)$ & $0.34(0.14)$ & $0.38(0.16)$ \\
YE & 0.2 & $1,942(404)$ & $0.53(0.21)$ & $0.66(0.26)$ \\
SP and YE & & $2,466(574)$ & $0.87(0.37)$ & $1.17(0.49)$ \\
AU and YE & & $2,768(610)$ & $1.16(0.45)$ & $1.67(0.64)$ \\
ST and YE & & $2,480(564)$ & $0.85(0.34)$ & $1.07(0.44)$ \\
YE & 0.3 & $3,099(726)$ & $1.38(0.53)$ & $1.99(0.76)$ \\
SP and YE & & $3,957(1,003)$ & $2.14(0.85)$ & $3.27(1.29)$ \\
AU and YE & & $4,459(1,148)$ & $2.74(1.09)$ & $4.49(1.80)$ \\
ST and YE & & $4,017(1,016)$ & $2.10(0.84)$ & $3.02(1.21)$ \\
\hline
\end{tabular}

Values in parentheses denote SE

\begin{tabular}{lll}
\hline & Spring & Autumn \\
\hline 2003 & $5.37^{\mathrm{d}}$ & 2.48 \\
2004 & 2.40 & 1.09 \\
2005 & $5.42^{\mathrm{d}}$ & 3.12 \\
2006 & 2.04 & 1.80 \\
2007 & 1.19 & 1.40 \\
2008 & 2.59 & 3.40 \\
2009 & 2.71 & 2.74 \\
2010 & 1.61 & 1.84 \\
2011 & 2.42 & \\
Mean $A^{\mathrm{a}}$ & 2.86 & 2.23 \\
Mean $N^{\mathrm{b}}$ & 2.14 & \\
Mean $S^{\mathrm{c}}$ & 5.40 & \\
\hline a & \\
${ }^{2}$ Mean RPS value of all years \\
b Mean RPS & value & of normal \\
year classes \\
c Mean RPS & value & of strong \\
year classes \\
d RPS of strong year classes
\end{tabular}

class appearance), spring spawning season in a normal year, and autumn spawning season, respectively (Table 3 ). In the bootstrap method, the RPS values of normal years, and those in which strong year classes were apparent, were selected randomly from observed values for each brood in each year (Table 3).

\section{Discussion}

In Eq. (6) for the VPA we assumed the fishing mortality coefficient in the latest years to be the average of previous fishing mortality coefficient values. As there have been no substantial changes in the hairtail fishery, such as in fishing effort or method, the assumption of Eq. (6) is considered to be satisfied. In addition, the sensitivities of $G$ in Eq. (6) revealed the effect of different $G$ to be minor. Retrospective analysis also revealed no trend (either increasing or decreasing) in the capability of prediction for the latest year. Accordingly, we believe stock abundance in this area to be accurately estimated. To estimate future recruitment, Eqs. (14) and (15) included only RPS and spawning stock biomass values; we did not include limitation of recruitment as a function of spawning stock biomass level, as used in Beverton and Holt [16] and hockey stick [17] models. At most, the predicted biomass after 20 years was about 12,000 t. In 1983, the catch reached more than 10,000 t. The biomass is not predicted to reach a level where the limitation of recruitment by spawning stock biomass level should be considered. 
Stock assessment by seasonal brood analysis showed a clear decreasing trend in the spring brood (Fig. 3). RPS values for the spring brood were higher in 2003 and 2005 than they were in other years, though autumn brood RPS values were relatively stable. The high recruitment potential of the spring brood in 2003 and 2005 indicated that these were strong year classes. Differences in RPS over time for spring and autumn broods contributed to fluctuations in both stocks. The recent decrease in hairtail landings is largely a consequence of low-level spring-brood recruitment. Juvenile hairtail prey include copepods, mysids, and juvenile fish, such as the Japanese anchovy Engraulis japonicus [18, 19]. The relationship between the spring-brood spawning peak and prey abundance might contribute to strong year classes. Although the mechanism is not clear, ecosystem models, such as individual based model [20], that take prey-predator dynamics into consideration (e.g., models that consider relationships between nutrients, phytoplankton, copepods, anchovy, and hairtail) may be useful for a better understanding of recruitment dynamics.

The main catchable hairtail population was 1 and 2 years of age. Therefore, in the event of a strong year class, larger catches should occur in successive years, as observed in 2003 and 2005 (Fig. 3). Future catch predictions reveal that an increase of recruitment in strong year classes contributes to greater catches in subsequent years (Fig. 8), as occurred several times up to 2007, though the lack of a strong year class after 2007 has resulted in a decrease in recent catches. In the event that similar processes affected historic populations, then recruitment conditions from 1993 to 1995 were better than in other years. The fact that landings have decreased over time suggests that fishing pressure has been constantly high.

YPR and SPR analyses reveal current fishing pressure to be higher than $F_{\text {max }}, F_{0.1}$ and $F_{30 \% \text { SPR }}$ reference points, and that the fishing pressure needs to be reduced by at least $20 \%$ of current levels for the fishery to remain sustainable. Predicted stocks in each management scenario indicate reduced fishing pressure will lead to rapid increases in future stock abundance (Fig. 8; Table 2). Moreover, reduced fishing pressure in each spawning season, and years after the appearance of strong year classes, are additional, effective management strategies that will contribute to enhancing future stock abundance. For hairtail, strong year classes can be detected during research sampling based on the incidence of juvenile fish during winter (Tokumitsu, unpublished data). Although a strong year class occurs only intermittently, reducing fishing pressure when one does occur would facilitate stock recovery. Such management strategies have been applied to Japanese chub mackerel [21].

The effects of four types of management, YR, SP, AU, and ST, and their combination were evaluated in this study. As shown in Fig. 8, ST decreases the catch amount in the year after a strong year class occurrence. When importance is attached to the stability of the yearly catch, a combination of these types of management that result in the least fluctuation in catch, i.e., YE, SP, AU, might be best. Though we cannot be certain when strong year classes will occur, when they do they have the potential to contribute to stock recovery and increased annual landing. Therefore, it is important to manage them, and to use their occurrence in spring broods to improve fishery management, rather than to exploit them without limitation. Although it is difficult to obtain consensus among different types of fisheries working in different areas, early implementation of management strategies like this will ultimately contribute to more rapid recovery and sustainable exploitation of fisheries resources. Using the stock structure and resource management results of this study, we elsewhere discuss the development of effective fishing gear [22] and a transdisciplinary approach to coastal fisheries co-management [23] for improved resource management.

Acknowledgements This research received funding from the Marine Fisheries Research and Development Center, Fisheries Research Agency of Japan (Empirical Research Project for Marine Fisheries Resource Development: Hairtail Trolling Line Fishery around the Bungo Channel, Fiscal Year 2011-2013).

Open Access This article is distributed under the terms of the Creative Commons Attribution 4.0 International License (http://creativecommons.org/licenses/by/4.0/), which permits unrestricted use, distribution, and reproduction in any medium, provided you give appropriate credit to the original author(s) and the source, provide a link to the Creative Commons license, and indicate if changes were made.

\section{Appendix 1}

See Table 4. 


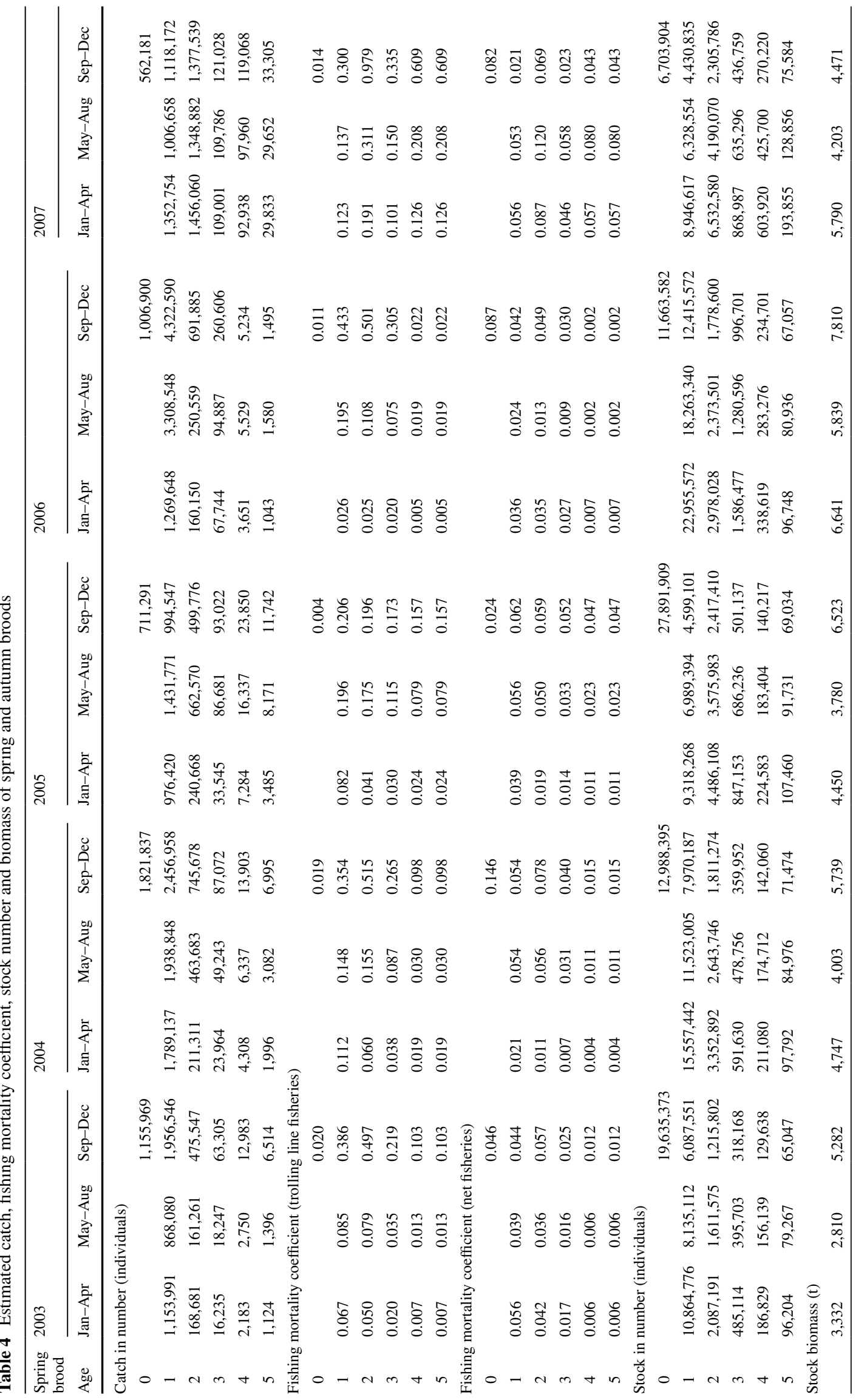




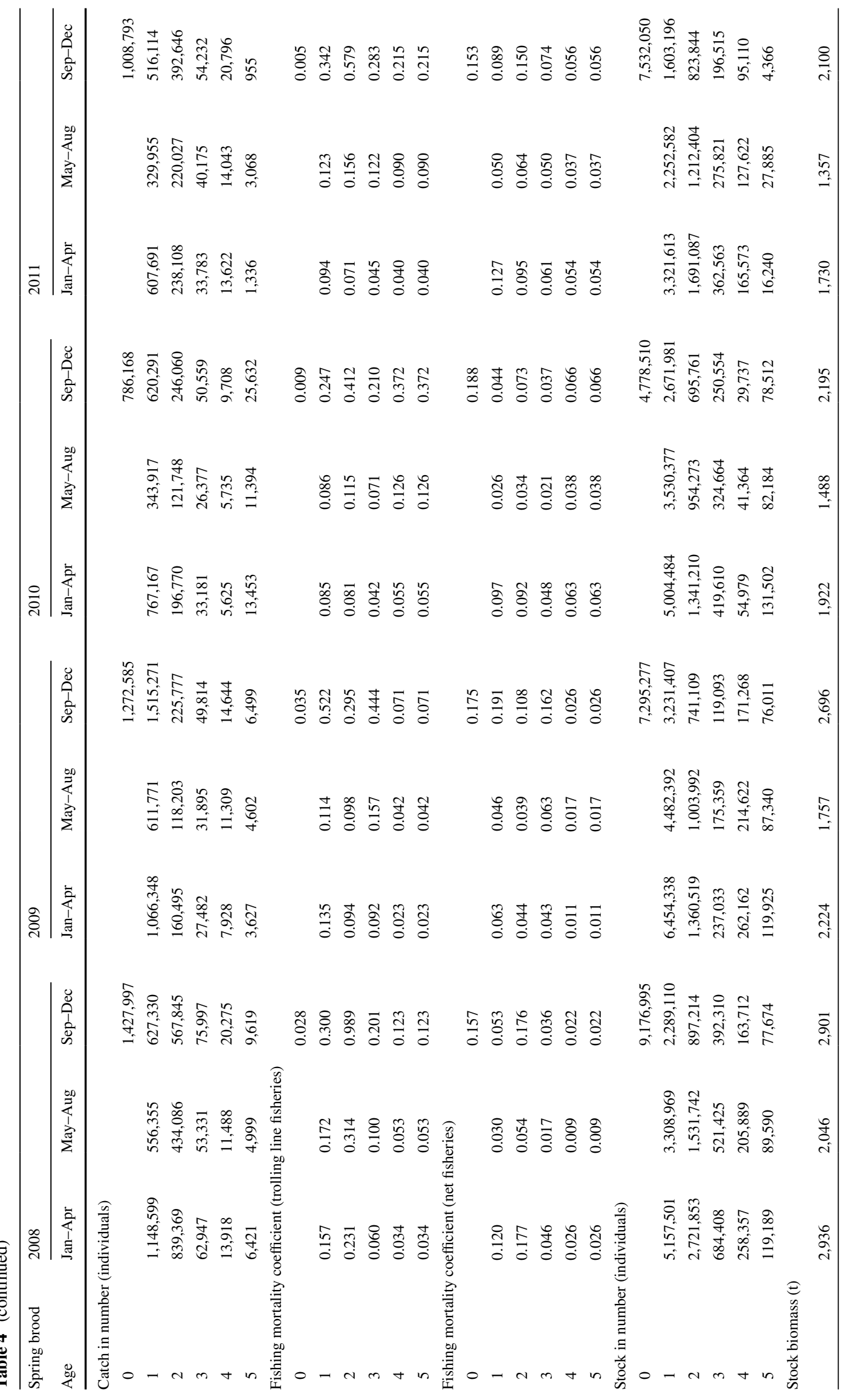




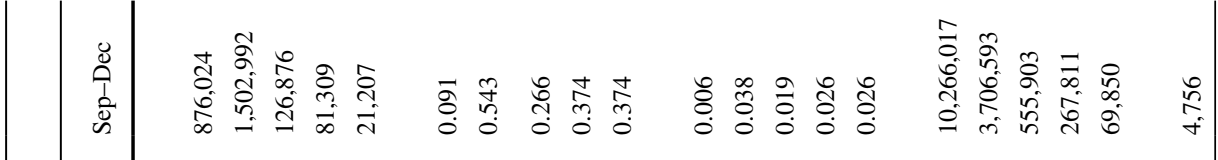

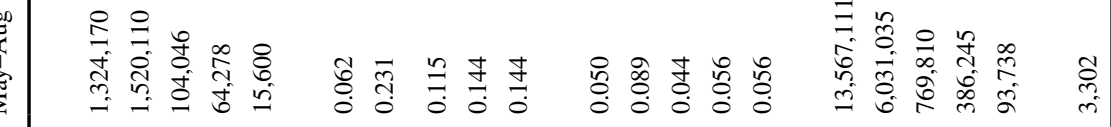

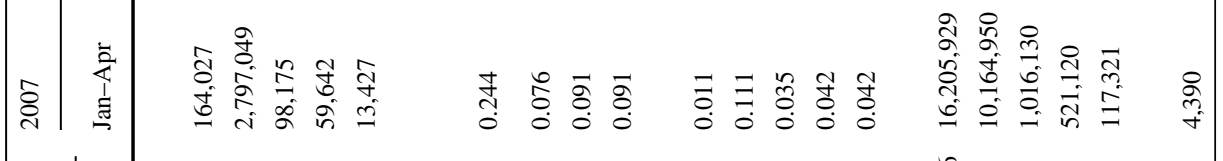

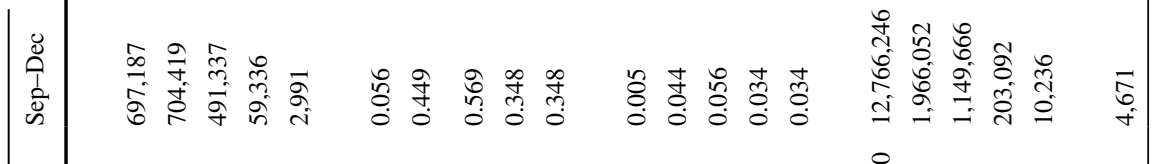 $\stackrel{\infty}{\nexists ٍ}$

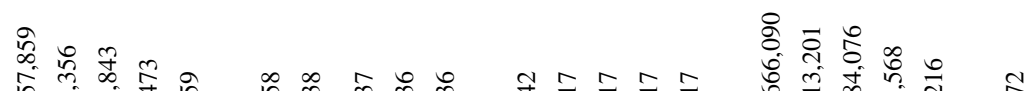

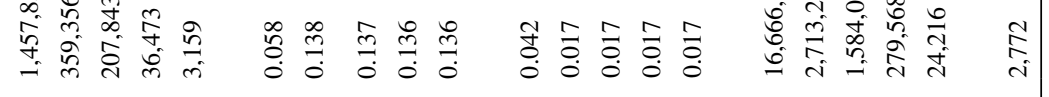

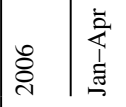

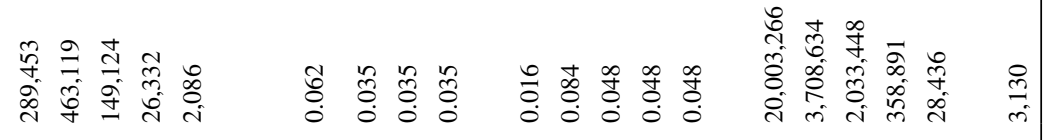

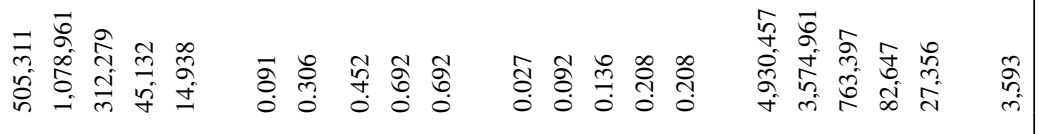

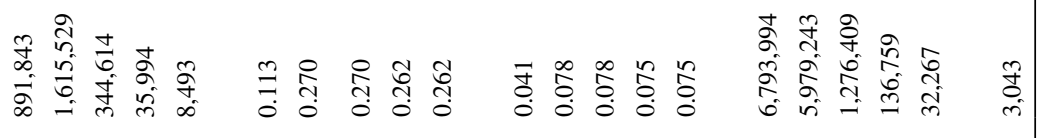

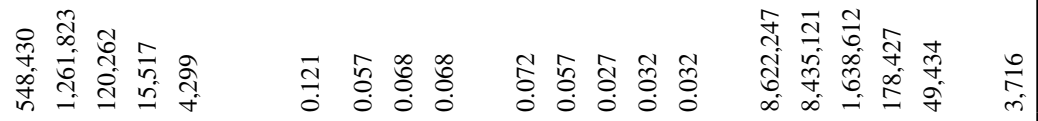

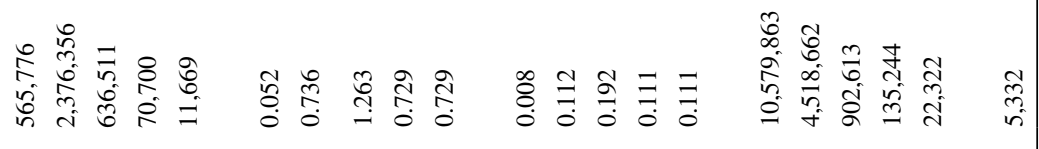

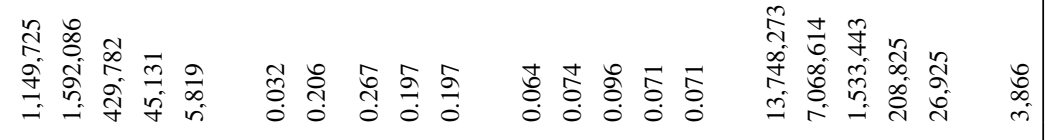

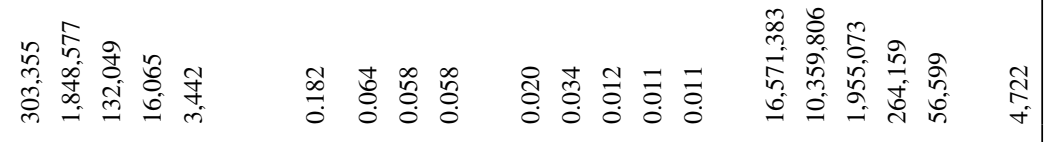

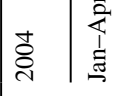

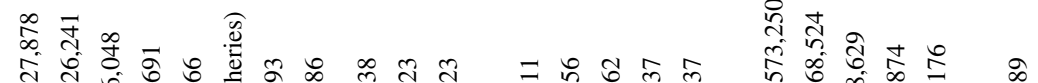

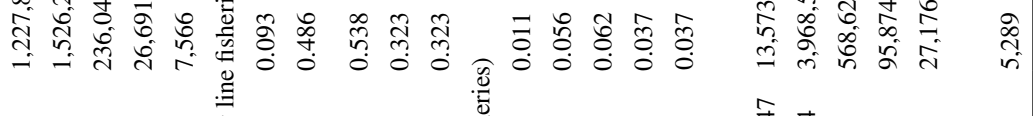

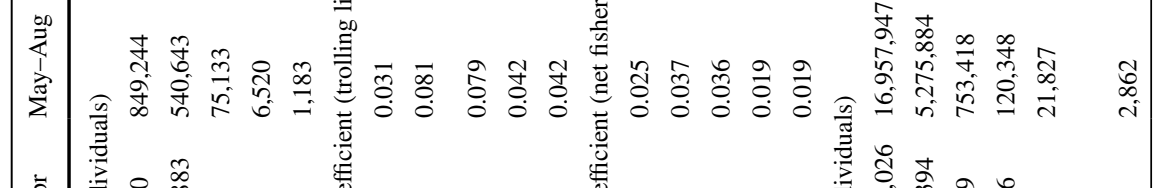 离

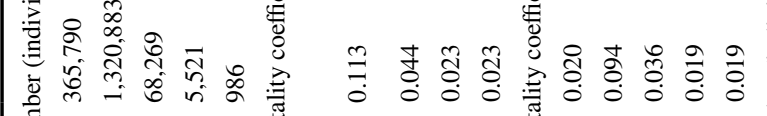 造吉

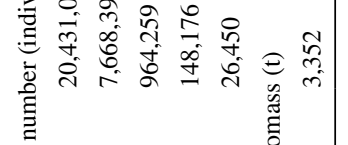




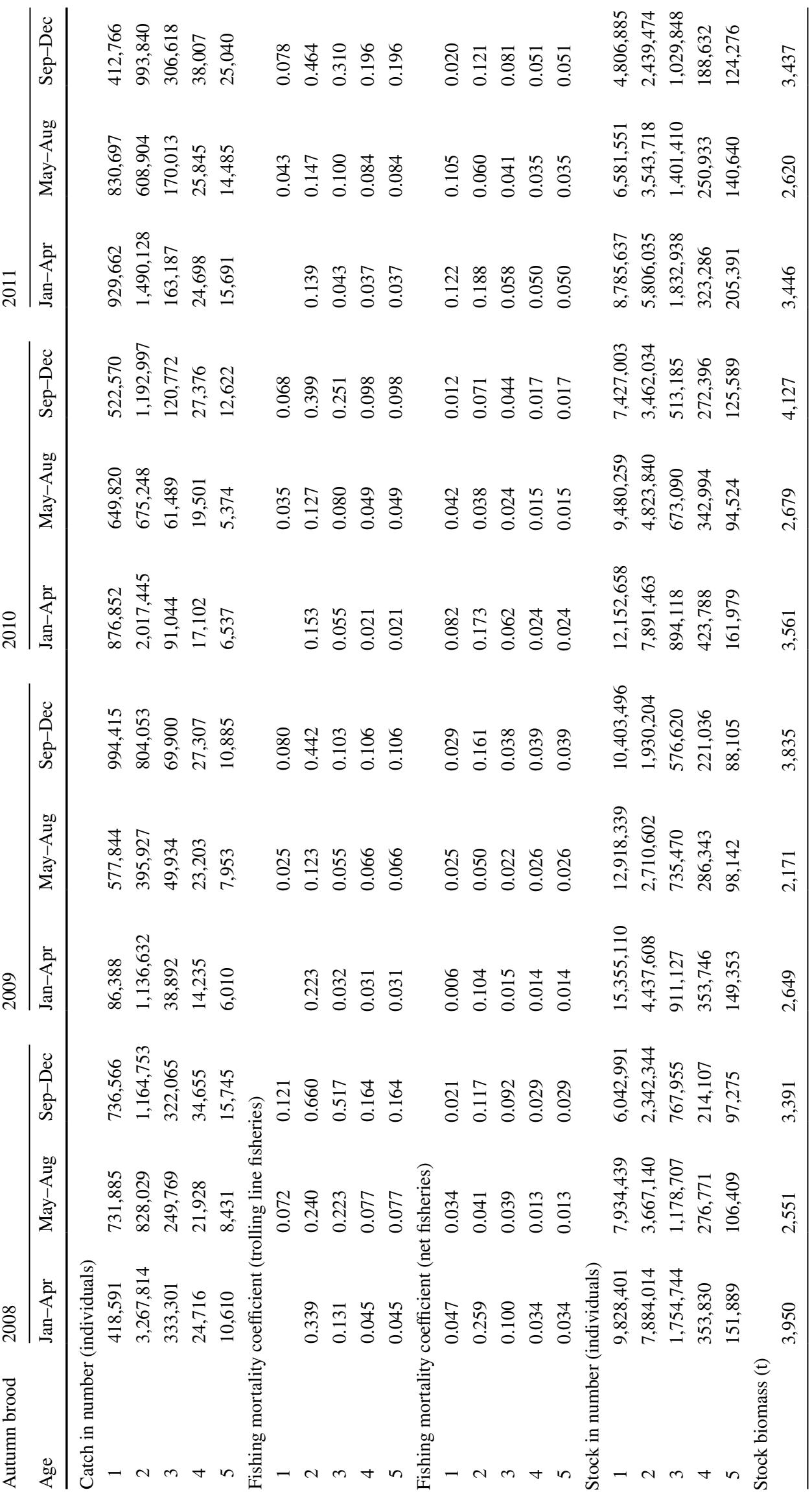




\section{References}

1. Yamada U, Tokimura M, Horikawa H, Nakabo T (2007) Fishes and fisheries of the East China and Yellow Sea. Tokai University Press, Hadano (in Japanese)

2. Sanada S, Doiuchi R, Okazaki T, Hayashi Y, Yanagawa S (2011) Resources investigation and fisheries stock management of hairtail Trichiurus japonicus, in south-western waters of Japan. Fish Biol Oceanogr Kuroshio 12:73-77 (in Japanese)

3. Aonuma Y, Sakai T (2015) Stock assessment and evaluation for hairtail of East China Sea and Sea of Japan stock (fiscal year 2014). In: Marine fisheries stock assessment and evaluation for Japanese waters (fiscal Year 2014/2015). Fisheries Agency and Fisheries Research Agency of Japan, Tokyo, pp 1365-1379 (in Japanese)

4. Yanagawa S (2009) Fisheries biology of the hairtail Trichiurus japonicus in the Bungo Channel and near coastal waters, Japan. $\mathrm{PhD}$ dissertation, Tokyo University of Marine Science and Technology, Tokyo (in Japanese)

5. Watari S, Tokumitsu S, Hirose T, Ogawa M (2014) Age and size brand of the hairtail by spring and autumn brood in the Bungo Channel and Iyo-nada, Japan. Fish Biol Oceanogr Kuroshio 15:75-80 (in Japanese)

6. Suzuki K, Kimura S (1980) Fishery biology of the ribbon fish, Trichiurus lepturus, in Kumano-Nada, central Japan. Bull Fac Fish Mie Univ 7:173-192 (in Japanese)

7. Sakamoto T (1982) Studies on the fishery biology of the ribbon fish, Trichiurus lepturus, in the Kii Channel. Wakayama Pref Fish Exp Stat Special issue :1-113 (in Japanese with English abstract)

8. Tokumitsu S, Hashida D, Hotta T (2013) Resource analysis of hairtail Trichiurus japonicus in the Bungo Channel and the surrounding sea in Japan. Fish Biol Oceanogr Kuroshio 14:93-97 (in Japanese)

9. Doiuchi R, Yoshimi K, Hotta T (2013) Stock assessment of ribbon fish Trichiurus japonicas in Kii Channel, Japan. Fish Biol Oceanogr Kuroshio 14:99-103 (in Japanese)

10. Pope JG (1972) An investigation of the accuracy of virtual population analysis using cohort analysis. ICNAF Res Bull 9:65-74

11. Kurosaka K, Hirose T, Takada J, Okaya Y, Tsuru S, Oda K, Satani M, Ogawa M (2014) Marine fisheries resource rational utilization development project report of 2012. (Hairtail trawling line fishing around the Bungo Channel) JAMARC. Fisheries Research Agency, Yokohama (in Japanese)

12. Tanaka $S$ (1960) Studies on the dynamics and the management of fish populations. Bull Tokai Reg Fish Res Lab 28:1-200 (in Japanese)

13. Lassen H, Medley P (2001) A practical manual for stock assessment. FAO Fisheries Technical Paper. No. 400. Rome

14. Mace PM (1994) Relationships between common biological reference points used as thresholds and targets of fisheries management strategies. Can J Fish Aquat Sci 51:110-122

15. Gulland JA, Boerema LK (1973) Scientific advice on catch level. Fish Bull 71:325-335

16. Beverton RJH, Holt SJ (1957) On the dynamics of exploited fish population. Chapman \& Hall, London (Facsimile reprint 1993)

17. Barrowman NJ, Myers RA (2000) Still more spawner-recruitment curves: the hockey stick and its generalizations. Can J Fish Aquat Sci 57:665-676

18. Munekiyo M, Kuwahara A (1985) Food habits of ribbon fish in the western Wakasa Bay. Nippon Suisan Gakkaishi 51:913-919 (in Japanese with English abstract)

19. Doiuchi R, Yasue N, Takeda Y (2012) Trophic level of Trichiurus japonicus in the Kii Channel Japan, based on carbon and nitrogen stable isotope ratios. Nippon Suisan Gakkaishi 78:479-481 (in Japanese)

20. Zenitani H, Kono N, Watari S (2017) Impact of the jellyfish Aurelia aurita on the anchovy fishery stock in Hiuchi-nada, central Seto Inland Sea, Japan. Bull Jpn Soc Fish Oceanogr 81:1-17 (in Japanese with English abstract)

21. Makino M (2011) Fisheries management in Japan: its institutional features and case studies, vol 34. Springer, Dordrecht

22. Hirose T, Sakurai M, Watari S, Ogawa M, Makino M (2017) Conservation of small-size hairtail Trichiurus japonicus by using large-size artificial bait and the effect on the trolling line fishery. Fish Sci. doi:10.1007/s12562-017-1142-9

23. Makino M, Watari S, Hirose T, Oda K, Hirota M, Takei A, Ogawa M, Horikawa H (2017) A transdisciplinary research of coastal fisheries co-management: a case of hairtail Trichiurus japonicus trolling line fishery around the Bungo Channel, Japan. Fish Sci. doi:10.1007/s12562-017-1141-x 